\title{
Holy fire in an HIV-positive man: a case of 21st-century ergotism
}

\author{
Georg Fröhlich MD, Vladimir Kaplan MD MPH, Beatrice Amann-Vesti MD
}

Previously published at www.cmaj.ca

A 29-year-old HIV-positive man receiving antiretroviral therapy was referred for circulatory evaluation because of paresthesiae and coldness of the left upper extremity. For two days, he had noticed difficulties with writing, and his left hand felt clumsy. Antiretroviral treatment with emtricitabine-tenofovir and lopinavir-ritonavir had been started two months earlier. The patient denied consumption of illicit drugs, including cocaine and cannabis, or intake of any additional medications. There were no clinical signs suggestive of HIV-related illnesses.

Physical examination showed that the left hand was pale (Figure 1), and arterial pulses were absent at the left wrist. The heart rate was 60 beats/min, and arterial blood pressure was $105 / 65 \mathrm{~mm} \mathrm{Hg}$ on the left arm and 115/65 $\mathrm{mm} \mathrm{Hg}$ on the right arm. Oscillography showed significant reduction of perfusion of the left forearm. The results of duplex ultrasonography were consistent with high-grade, long-segment stenosis of the distal axillary artery. No signs of atherosclerosis were observed, and no intimal thickening was present.

Over the course of the day of admission, the patient's symptoms improved intermittently. Repeat duplex ultrasonography showed that stenosis of one part of the artery had almost resolved, but there was de novo stenosis of a different segment. Angiography was performed to exclude additional distal embolization and to confirm the diagnosis of intermittent vasospasm (Figure 2). However, even after intra-arterial

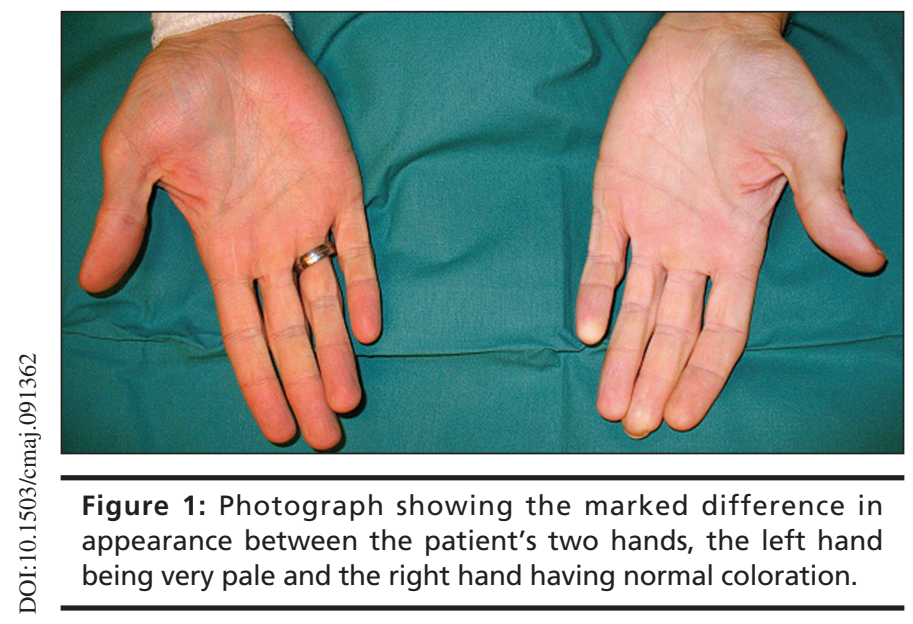

\section{Key points}

- Coadministration of ergotamine and protease inhibitors may cause severe ergotism because of a drug-drug interaction.

- Patients receiving antiretroviral therapy should be informed about potentially harmful interactions with putative harmless over-the-counter medications.

- The prognosis for ergotismresulting from an interaction between ergotamine and protease inhibitors appears favourable if both drugs are promptly discontinued.

administration of $200 \mu \mathrm{g}$ nitroglycerin, spasm of the radial and ulnar arteries did not fully resolve.

The patient was asked again about use of any additional medications or illicit drugs. He mentioned a trip to Egypt that he had taken three weeks before the symptoms started. During his stay in Egypt, he had experienced a severe migraine headache. He consulted a local physician, who prescribed ergotamine tartrate $1 \mathrm{mg}$ per day orally, which the patient had taken for two weeks, until the day before admission. Ergotamine has numerous potential interactions with HIV medications (Box 1). We concluded that the patient was experiencing the rare condition of ergotism caused by such an interaction.

We initiated vasodilation therapy with intravenous administration of prostacyclin, dermal application of nitroglycerin and anticoagulation with low-molecular-weight heparin to prevent secondary thrombosis. Within six days, the ischemic symptoms of the left arm had disappeared. The patient's blood pressure and oscillographic results became normal, and the patient was discharged in good condition without any specific treatment, other than his pre-existing HIV therapy. Further follow-up over two months was uneventful.

\section{Discussion}

Ergotism results from ergot poisoning and is traditionally caused by the ingestion of alkaloids produced by the fungus

From the Department of Internal Medicine (Fröhlich, Kaplan) and the Clinic for Angiology (Amann-Vesti), University Hospital Zurich, Zurich, Switzerland

CMAJ 2010. DOI:10.1503/cmaj.091362 
Claviceps purpurea, which infects rye and other cereals. The symptoms can be divided into effects on the central nervous system, such as hallucination, mania, psychosis and seizures, and vasoconstrictive effects, which are caused by strong $\alpha$ agonistic effects and central sympatholysis. ${ }^{1,2}$ The direct consequences are limb ischemia with paresis, impairment of sensation and ultimately loss of the affected extremity. In the Middle Ages, painful ergotism (characterized by a sensation of burning) was known as "Holy Fire" or "St. Anthony's fire," named for the monks of the Order of St. Anthony (Figure 3), who cared for affected patients.

Today, ergotamine intoxication is rare in Western countries, but it has been reported after ingestion of certain ergotbased drugs that are commonly prescribed for treatment of migraine headache, such as methylergometrine, ergotamine or ergotoxine. ${ }^{1}$ Ergot-based drugs are available over the counter in most European countries and the United States. In Canada, they are available only by prescription, except in homeopathic preparations.

Recommended ergotamine doses, including the dose taken by the patient described here, have been shown to be safe and are far below the critical level associated with ischemic events. ${ }^{1}$ However, ergotamines are substrates of the cytochrome P450 3A4 isozyme (CYP3A4), with extensive first-pass metabolism and very low bioavailability $(<5 \%)$. As a result, coadministration with certain antiretroviral drugs and other potent CYP3A4 inhibitors (Box 1) can cause a pronounced increase in ergotamine levels, with potentially severe toxic effects. ${ }^{1,3}$

Searching PubMed, we identified 11 similar cases of ergotism after concomitant use of ergotamine and antiretroviral therapy for HIV treatment (for details, see Appendix 1, available at www.cmaj.ca/cgi/content/full/cmaj.091362/DC1). Six of the 11 patients were men. The mean age was 36.9 years, and HIV infection had been treated for 37.5 (range 0.3-60) months. On average, the patients had consumed ergotamine for 4.9 days, and the onset of symptoms was 4 (range 0.5-10) days after initiation of ergotamine consumption. Eight of the patients recovered fully within 10 (range 3-18) days. Interestingly, there were no cases of coronary involvement. Three of the patients had received the prescription for ergotamine from their physicians.

\section{Box 1: Potent inhibitors of cytochrome P450 3A4 isozyme that are contraindicated with concomitant use of ergotamines*}

- Protease inhibitors

- Amprenavir,
fosamprenavir
- Darunavir
- Indinavir
- Lopinavir
- Nelfinavir
- Ritonavir
- Saquinavir
- Tipranavir

- Non-nucleoside reverse transcriptase inhibitors

- Efavirenz

- Nevirapine

- Macrolide antibiotics

- Clarithromycin

- Erythromycin

- Azole antimycotics

- Fluconazole

- Itraconazole

- Ketoconazole

- Posaconazole

- Voriconazole

- Antiarrhythmics

- Amiodarone

- Diltiazem

- Verapamil

- Antidepressants

- Fluoxetine

- Fluvoxamine

- Nefazodone

- Food

- Roxithromycin

- Spiramycin

- Telithromycin

*Adapted from Wooltorton.
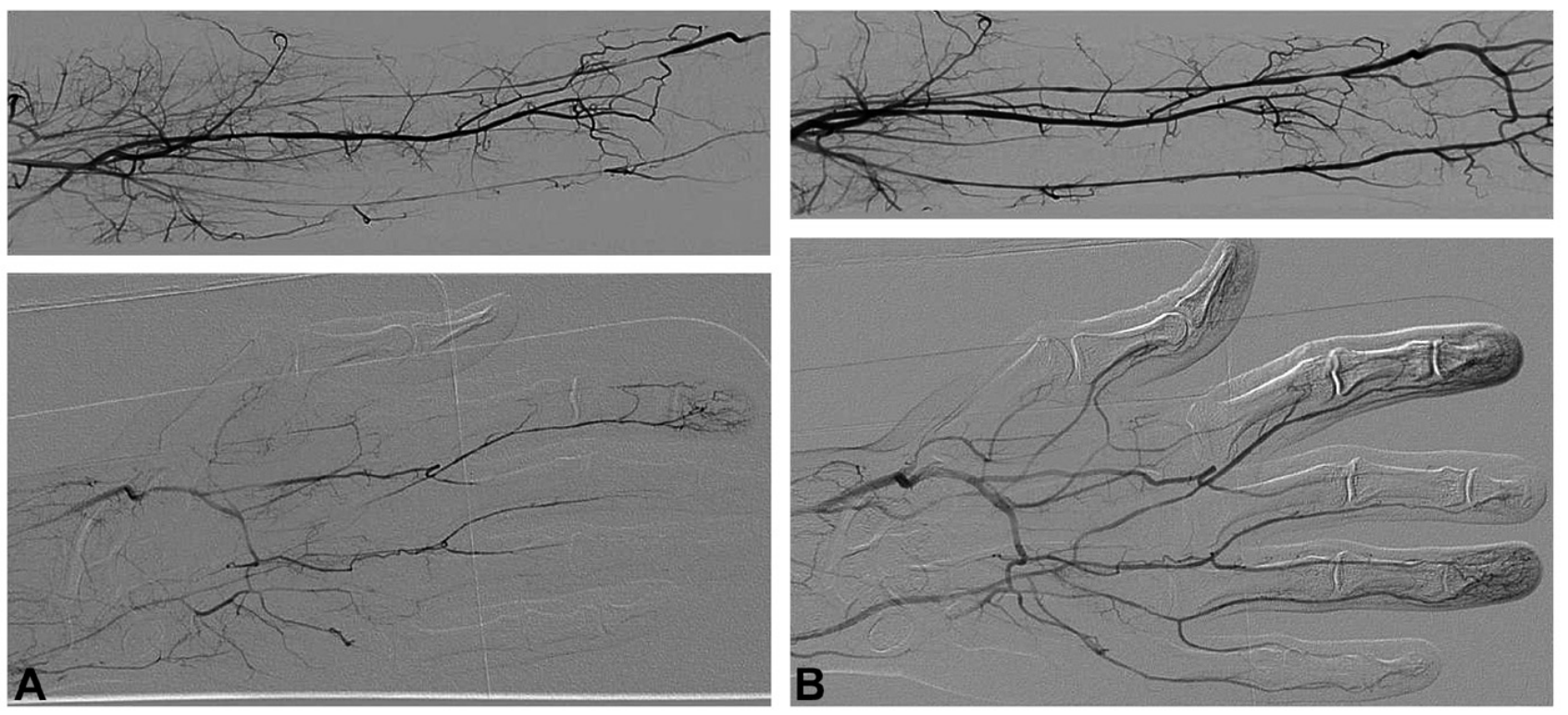

Figure 2: Angiography of the left forearm and left hand before $(A)$ and after $(B)$ intra-arterial injection of nitroglycerin. 


\section{Treatment}

The treatment recommendations for ergotism are similar to those for other vasospasm-related illnesses, such as Raynaud phenomenon or variant angina pectoris. Because of the low incidence of severe ergotism, evidence for specific treatment options is based mainly on case reports.

According to the cases that we reviewed, the first and most important step in treating vasospastic symptoms is immediate withdrawal of ergotamine. In most cases, the patients recovered fully after discontinuation of ergotamine. Discontinuation of the HIV medication also seemed to have favourable results.

If there has been long-term ergotamine use, the vasospasms may continue for several days, and additional therapeutic interventions should be considered. The patient should abstain from other agents causing vasospasm, such as caffeine, nicotine and $\beta$-blockers, and should avoid exposure

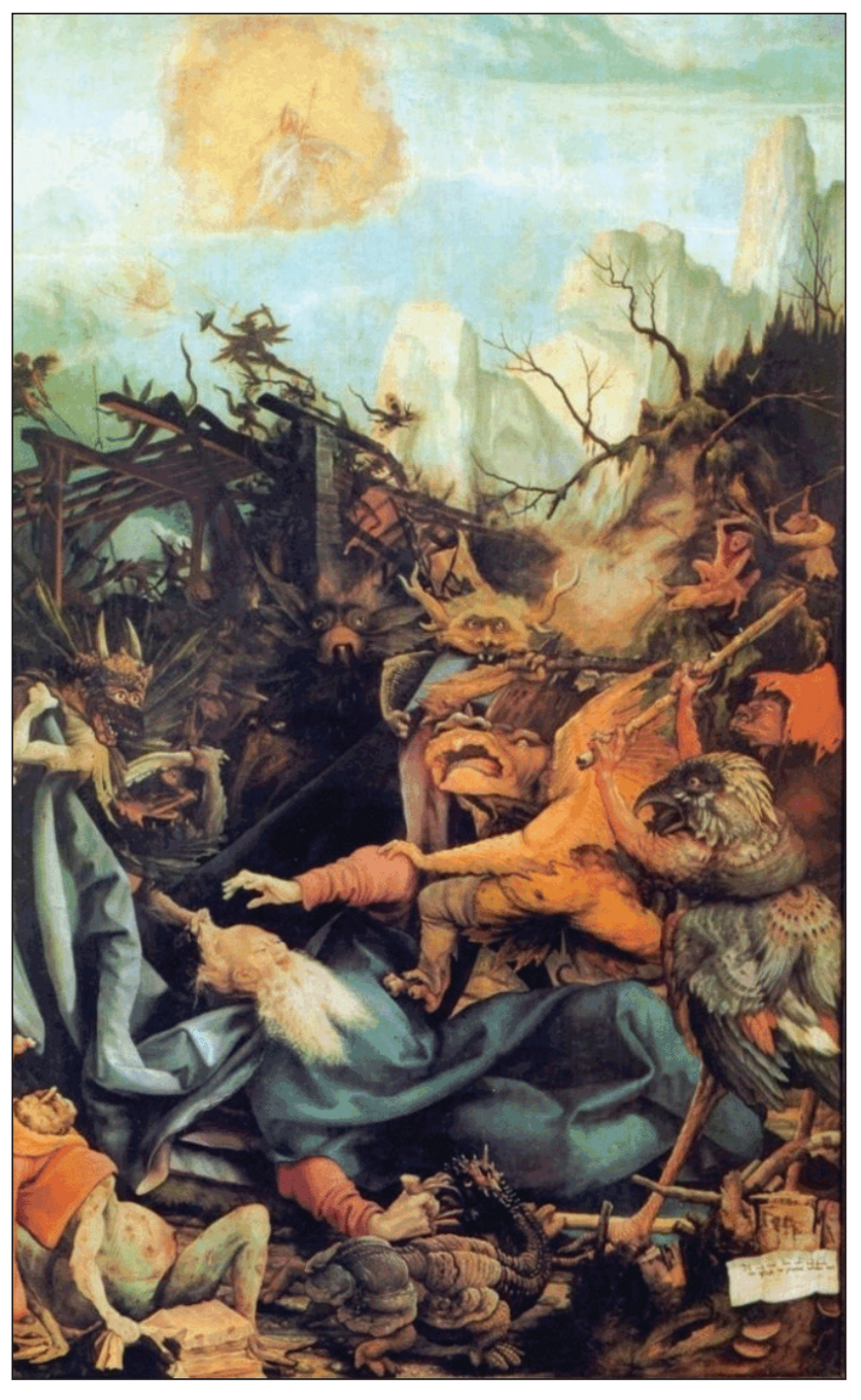

Figure 3: Image from the Isenheim Altarpiece by Grünewald, Musée d'Unterlinden, Colmar, France. This depiction shows St. Anthony (at centre of the image) fighting the demons and protecting a man suffering from "Holy Fire" (left lower part of the image). to cold temperature. ${ }^{2}$ The positive effects of vasodilator therapy with prostaglandins, ${ }^{4}$ calcium-channel blockers ${ }^{5}$ or nitroglycerine-nitroprusside ${ }^{6}$ in patients with critical ischemia have been published in several case reports.

Balloon angioplasty was used in two patients with severe persistent vasospasm refractory to vasodilator therapy. ${ }^{7}$ Interventional therapy with aspiration of thrombotic material or thrombolysis might be considered in cases involving thrombotic occlusion or distal embolization. ${ }^{8}$

\section{Prevention}

Severe ergotism with life-threatening ischemic complications may occur because of coadministration of ergotamine to patients being treated with protease inhibitors. To prevent such complications, patients receiving antiretroviral therapy should be informed about potential drug-drug interactions and should avoid self-administration of over-the-counter drugs without discussion with a relevant health professional.

This article has been peer reviewed.

Competing interests: None declared.

Acknowledgements: The authors thank Dr. Thomas Meier for his help with photo documentation and writing, Dr. Natascia Corti for her pharmacologic advice and Dr. Anna Bartosch-Carlile for her support in writing the article.

\section{REFERENCES}

1. Tfelt-Hansen PC, Koehler PJ. History of the use of ergotamine and dihydroergotamine in migraine from 1906 and onward. Cephalalgia 2008;28:877-86.

2. Molkara AM, Abou-Zamzam AM Jr, Teruya TH, et al. Chronic ergot toxicity presenting with bilateral external iliac artery dissection and lower extremity rest pain. Ann Vasc Surg 2006;20:803-8.

3. Wooltorton E. Risk of stroke, gangrene from ergot drug interactions. CMAJ 2003;168:1015.

4. Piquemal R, Emmerich J, Guilmot JL, et al. Successful treatment of ergotism with iloprost — a case report. Angiology 1998;49:493-7.

5. Borges AA, Lin CC, Jabaji GJ, et al. Brachial artery stenosis secondary to ergotism and responsive to nifedipine. Postgrad Med 1986;80:263-5.

6. Carliner N, Denune DP, Finch CS Jr, et al. Sodium nitroprusside treatment of ergotamine-induced peripheral ischemia. JAMA 1974;227:308-9.

7. Shifrin E, Perel A, Olschwang D, et al. Reversal of ergotamine-induced arteriospasm by mechanical intra-arterial dilatation. Lancet 1980;2:1278-9.

8. Vila A, Mykietiuk A, Bonvehi $\mathrm{P}$, et al. Clinical ergotism induced by ritonavir Scand J Infect Dis 2001;33:788-9.

Correspondence to: Dr. Georg Fröhlich, University Hospital Zurich, Department of Internal Medicine, Raemistrasse 100, CH-8091 Zurich, Switzerland; GeorgMarcus.Froehlich@usz.ch

The section Cases presents brief case reports that convey clear, practical lessons. Preference is given to common presentations of important rare conditions, and important unusual presentations of common problems. Articles start with a case presentation (500 words maximum), and a discussion of the underlying condition follows (1000 words maximum). Generally, up to five references are permitted and visual elements (e.g., tables of the differential diagnosis, clinical features or diagnostic approach) are encouraged. Written consent from patients for publication of their story is a necessity and should accompany submissions. See information for authors at www.cmaj.ca. 